\title{
Storage structures for horticultural crops: a review
}

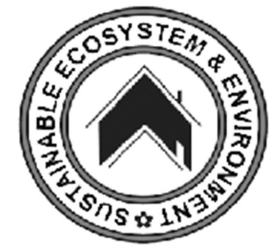

Kaur, J. 凶, Aslam, R., Afthab Saeed, P.

Received: 22.10.2020

Revised: 06.01.2021

Accepted: 20.01.2021

\begin{abstract}
Most of the horticultural crops are seasonal, having a relatively short harvesting season, and most of them are highly perishable. Hence, proper storage of the horticultural crops using appropriate methods would prolong their availability. The present article gives details about various storage structures classified into two categories, i.e., traditional storage/low-cost storage technologies and improved methods/ modern methods /high-cost storage technologies. Traditional storage structures can be beneficial for farmers needing a small-scale storage system. These systems include in-situ storage, sand and coir, clamps, pits, cellars, ventilated storage, and evaporative cooling. On the other hand, modern methods include refrigerated storages like cold storages, environment-controlled storage (controlled atmospheric storage), modified atmosphere storage, and hypobaric storage. All the storage methods are equally important and can provide high revenue to the farmers and food industries.
\end{abstract}

Key Words: Controlled atmospheric storage, evaporative cooling, horticulture, hypobaric, modified atmospheric packaging, storage

\section{Introduction}

India holds the second position in horticultural crop production globally, producing vegetables, fruits, coffee, cotton, and spices in large quantities (Rais and Sheoran, 2015). A large portion of such products is lost owing to bad storage practices, insects, and pests. The post-harvest losses associated with fruits and vegetables have been put in the range of 6-18\% (Nanda et al., 2012). Appropriate storage environment can improve the quality and marketability of horticultural produce. To obtain a suitable atmosphere for the produce, advanced provisions like temperature, air circulation, and relative humidity $(\mathrm{RH})$ control could be made. Also, the composition of air in the storage area could be regulated. Storage spaces can be classified based on the requirement of refrigeration, i.e., those requiring refrigeration and those that do not (El-Ramady et al., 2015). Clamps, ventilated structures, cellars, and evaporative cooling chambers are some conventionally used low-cost traditional storage structures. On the other hand, cold or refrigerated storage, modified atmospheric packaging (MAP), controlled atmospheric storage (CAS), hypobaric storage etc.

\section{Author's Address}

Department of Processing and Food Engineering, Punjab Agricultural University, Ludhiana

E-mail.: jassi.kaur51@yahoo.in are modern storage techniques used in large industries that provide more effective storage facilities. For developing countries like India, both types of structures stand equally important (Kale et al., 2016).

Traditional storage technologies/Low-cost storage technologies

Some of the low-cost storage structures have been discussed below:

a. In situ/ on-site/ field storage: The method of on-site storage involves postponing the crop harvest by leaving it in the soil. The crop is left in the soil till there is market demand. This method is mainly used for root, rhizomes, and tuber crops. A major disadvantage of this method is that land remains occupied where the produce is grown and new crop plantation might get delayed. This is quite analogous to some fruits which are left on the tree. It should be ensured that the crops are protected from pest and disease attacks, chilling, and freezing injuries (El-Ramady et al., 2015; Elansari et al., 2019).

b. Sand and Coir: In India, covering potatoes underground using sand and coir is a traditional storage practice. The crop can be stored for longer durations of time by this method (ElRamady et al., 2015). 
c. Pits: Pits are trenches in which a cavity is dug. These dug holes or cavities are lined with cut grass, wood shreds, sand, stubble, or soil (Figure 1) (Rees et al., 2012). They are prepared at the boundaries of the field and at an elevated point where there is a chance of less rainfall accumulation in the cultivated field (El-Ramady et al., 2015). The product stays cooler as compared to the air temperatures because of submersion in the pits. Tubers, such as potato, carrot, sweet potato, onion, turnip, parsnip, cabbages, and beets are covered up with straw and soil until the market demand for the crop arises (Elansari et al., 2019).

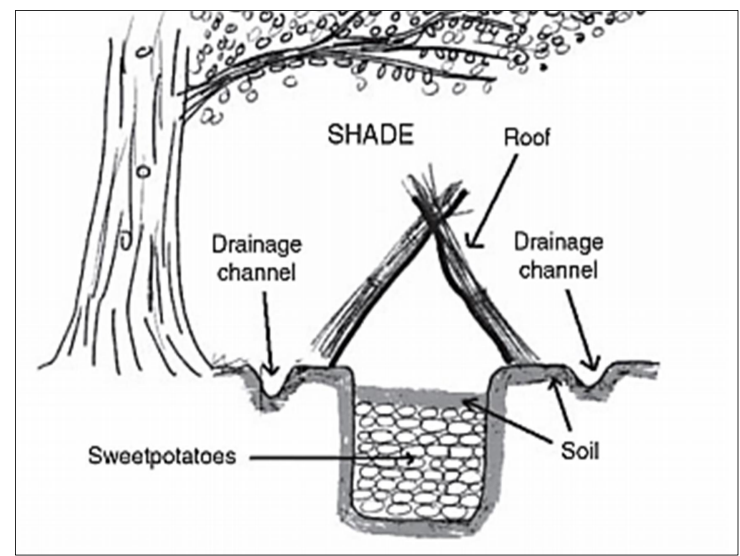

Figure 1. Pit storage for potatoes (adapted from Rees et al., 2012)

d. Clamps: Clamps are being traditionally used for storing potatoes in certain parts of the world (Figure 2). A clamp is commonly built at the edge of the field. It has a width of around 1-2.5 $\mathrm{m}$. After the piling up of potatoes in conical heaps, the dimensions are marked out. Quite often, a bed for the potatoes is made using straw on bare ground. The heap's central height is around one-third of the clamp's width, which is determined by the angle of repose of the heap. Rain runs over the structure through the straw, bent at the top to prevent possible spoilage. The compressed straw thickness must be in a range of 15 to $25 \mathrm{~cm}$. After two weeks, the clamp is covered with soil up to a depth of $15-20 \mathrm{~cm}$, which varies from place to place and depends on the environmental requirements (El- Ramady et al., 2015; Elansari et al., 2019).

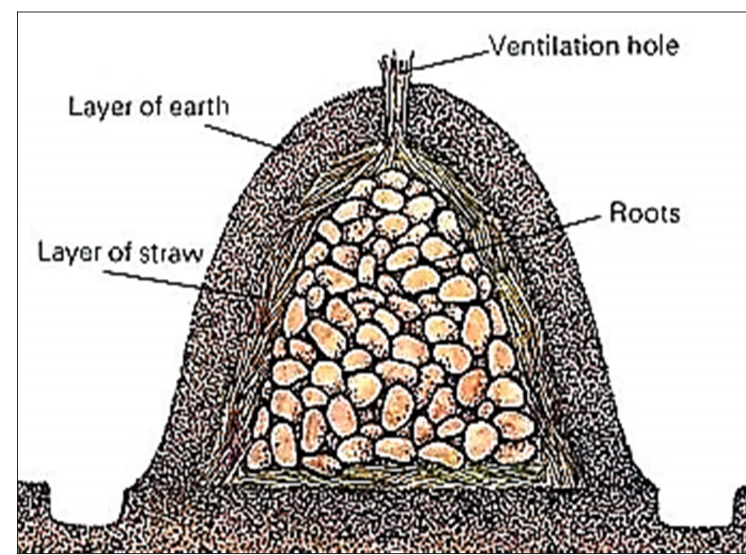

Figure 2. Root clamp cross-section (adapted from Kale et al., 2016)

Extra straw has been used in more tropical climates of India, to enhance ventilation, instead of soil. When the atmospheric temperature is very low, the second layer of insulation using soil and straw can also be made. The areas with a high atmospheric temperature can build chimney type air outlets at the top of the clamp to ensure proper ventilation. In the areas receiving heavy rainfall, the entry of rainwater into the clamp can be prevented by building it under a tree or a roof (Kale et al., 2016).

e. Cellars/ Root cellars: Another example of the traditional storage system is the cellar (Figure $3 \mathrm{a}$ and $3 \mathrm{~b}$ ). Cellars must ideally be dark, cold, and damp. They must be located by the basement walled-off area or garage having a significant area of optimum size and windows for proper ventilation (Elansari et al., 2019).

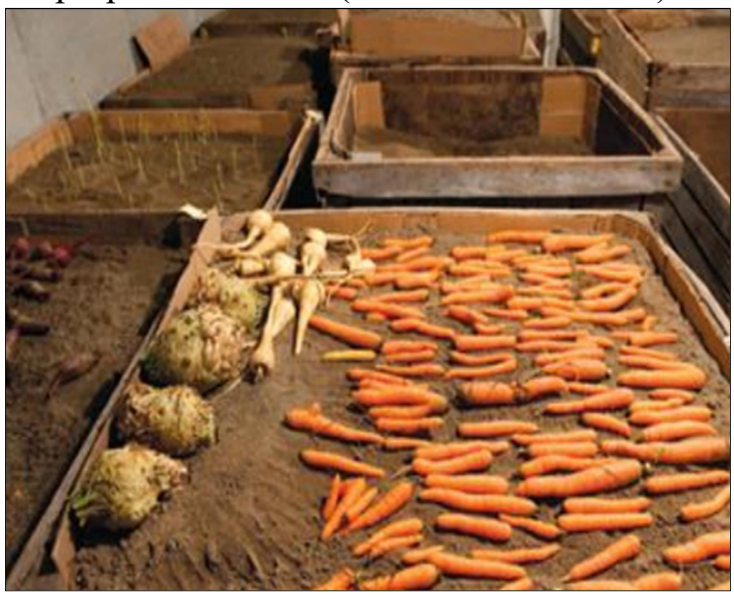

Figure 3a. Storage of produce in the cellar (adapted from Kale et al., 2016) 


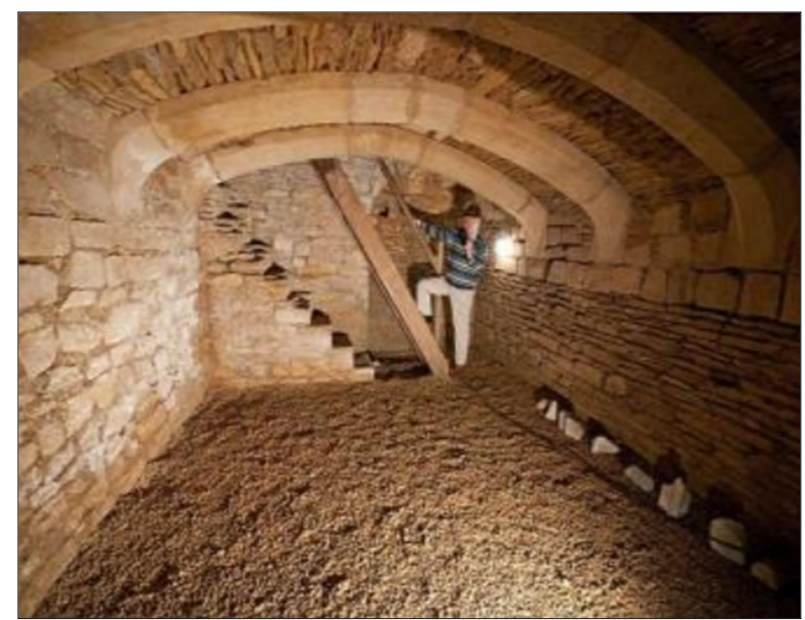

Figure 3b. A view of the cellar (adapted from Kale $e t$ al., 2016)

Following are some of the methods to construct storage cellars:

- Excavation of ground and building a shed or a house over the built cellar. Access can be provided from the top via a trap door

- Excavation through the hillsides is relatively easier and also permits rainwater drainage

- On rocky terrains, where it is difficult to excavate, a ground-level structure can be built. This structure, and the area surrounding it, can then be covered with rocks, earth, and sod (Kale et al., 2016).

The cellar can be used to store a wide variety of fresh produce, including beet, broccoli, potato, turnip, cabbage, carrot, pear, onion, Brussel sprouts, apple, and winter radish (El- Ramady et al., 2015; Elansari et al., 2019).

f. Ventilated storage structures: Ventilated storage structures have a flow of air that ensures nominal storage temperature. This air can be ventilated naturally or may be forced into the structure. The simplest system is the natural ventilation storage where the heat around the product is continuously removed by natural airflow along with humidity generated by product respiration. On the other hand, forced air ventilation uses auxiliary fans to increase the rate of heat and gas exchange. The air is forced through the stored crop with a velocity range of $10-13 \mathrm{~m} / \mathrm{s}$ (Elansari et al., 2019).

Natural ventilation: In the case of natural ventilation (Fig. 4) the heat of respiration and humidity from the product or other factors is removed through the natural flow of air around the produce. Any building or structure that protects the products and has gaps for proper airflow can be utilized for natural ventilation. Fresh produce is arranged in bulk, bins, pallets, bags, or boxes. One major disadvantage of natural ventilation is that the produce is left exposed to diseases, pests and adverse climatic environments that can damage the product quality (Elansari et al., 2019).

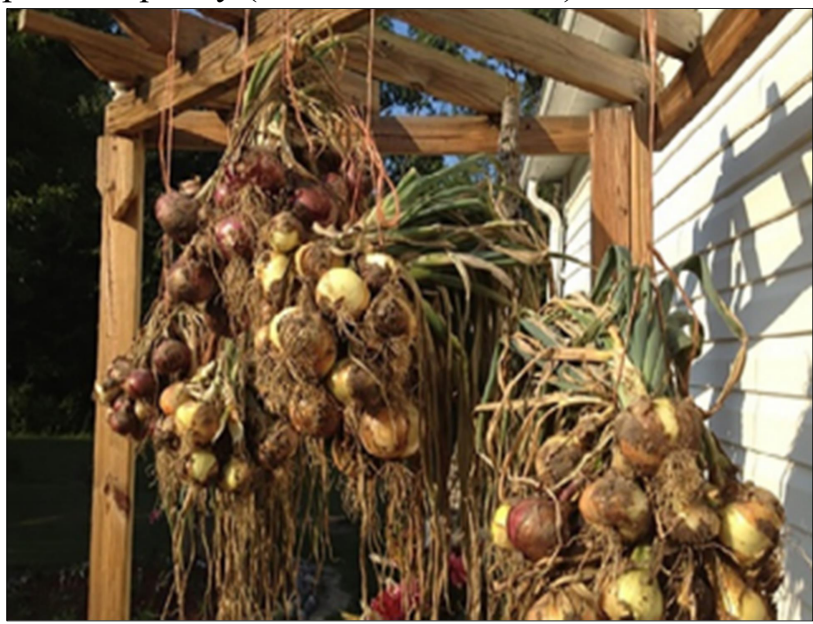

Figure 4. Storage in natural ventilation (adapted from Elansari et al., 2019)

Naturally ventilated structure can be employed for the storage of fruits and vegetables, including roots, tubers, onions, pumpkins, garlic, and hard white cabbage. Some of the improved storage structures for onions include high volume - bottom and side ventilated storage structure (25-50 tons capacity), concentric structures, low volume low-cost structures (5-10 tons capacity) made of bamboo, Nasik type storage structure (Figure 5), etc. (Kale et al., 2016).

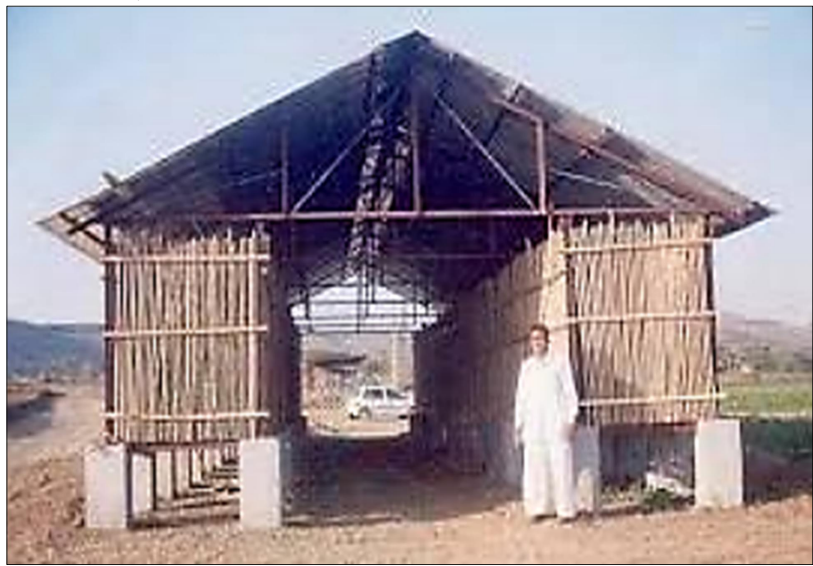

Figure 5. Ventilated storage- Nasik type (adapted from Kale et al., 2016) 
Kaur et al.

Table 1. Temperature drop chart (adapted from Kale et al., 2016)

\begin{tabular}{|c|c|c|c|c|c|c|c|c|c|}
\hline $\begin{array}{c}\text { Temperature } \\
\left({ }^{\mathbf{O}} \mathbf{C}\right)\end{array}$ & \multicolumn{10}{|c|}{ R.H. (\%) } \\
\cline { 2 - 12 }$y$ & $\mathbf{1 0}$ & $\mathbf{2 0}$ & $\mathbf{3 0}$ & $\mathbf{4 0}$ & $\mathbf{5 0}$ & $\mathbf{6 0}$ & $\mathbf{7 0}$ & $\mathbf{8 0}$ & $\mathbf{9 0}$ \\
\hline 10 & 4.0 & 4.5 & 5.5 & 6.0 & 7.0 & 7.5 & 8.0 & 9.0 & 9.5 \\
\hline 15 & 7.5 & 8.5 & 9.5 & 10.5 & 11.0 & 12 & 13 & 13.5 & 9.5 \\
\hline 20 & 11 & 12 & 13 & 14.5 & 15.5 & 16.5 & 17.5 & 18.5 & 19 \\
\hline 25 & 14.5 & 16 & 17 & 18.5 & 20 & 21 & 22 & 23 & 24 \\
\hline 30 & 17.5 & 19.5 & 21 & 22.5 & 24 & 25 & 26.5 & 28 & 29 \\
\hline 35 & 20 & 23 & 25 & 26.5 & 28.5 & 30 & 31.5 & 32.5 & 34 \\
\hline 40 & 23 & 26.5 & 29 & 31 & 32.5 & 34.5 & NA & NA & NA \\
\hline 45 & 26 & 29 & 32.5 & 35 & - & - & - & - & - \\
\hline 50 & 29 & 32.5 & 36.5 & - & - & - & - & - & - \\
\hline
\end{tabular}

Forced air ventilation: The exchange of gases and heat can be improved by forcing the air into the storage structures with the help of a fan. In this way, the storage space is utilized more efficiently. A perforated floor accommodates the air conducts, and the air is forced into the produce through them. To ensure a uniform distribution of air through the stored produce, fan capacity, conduct dimensions as well as loading patterns should be carefully designed. Designing must be done, considering that forced-air follows the path that provides the least resistance (El-Ramady et al., 2015).

g. Evaporative cool chambers: The cooling of produce in evaporative cooling chambers is done with the help of a physical phenomenon in which evaporation of a liquid into the atmosphere, typically into the surrounding air, results in cooling of an object or a liquid in contact with it (Basediya et al., 2013; Ndukwu and Manuwa, 2014). The humidity of the surrounding air controls the rate of cooling, hence determining its efficiency. This relationship can be understood from a temperature drop chart (Table 1) (Kale et al., 2016; Liberty et al., 2013).

\section{Benefits}

- Distress selling of fresh produce like fruits, vegetables, and flowers can be avoided

- It is suitable in rural areas as it is easy to operate and does not require special skills

- Locally available materials can be used for construction

- Capacity can be adjusted to the household need

- Fresh horticultural produce gets better marketability than ambient

- Nutritional value is retained
- Green and non-polluting

- Energy use can be reduced up to $70 \%$ in highly efficient evaporative cooling systems

- The moisture content of surrounding air is improved by evaporation that prevents the drying out of the produce, and hence, enhancing the shelf life

- Less cost-intensive

- Easy to fabricate and maintain

- Fruits and vegetables can be stored for 3-5 days without any substantial quality deterioration.

\section{Shortcomings}

- A constant supply of water is needed to keep the pads wet. Hence the water needs are significant.

- Space is needed in the vicinity of the house.

- Inappropriate water quality can damage the cooler.

- The evaporative cooler performance can be hindered by high dew point (humidity) conditions (Basediya et al., 2013)

Some of the evaporative cooling structures are explained below:

- Pot design: This is the simplest design of an evaporative cooler and can be used at home. A storage pot is placed inside a big pot that holds water. The product to be cooled is kept in the inner pot. One adaptation of this design is the Janata cooler (Figure 6), which has been developed by India's food and nutrition board (Roy and Khurdiya, 1985). In this, the storage pot is kept in an earthen bowl, which contains water. The pot is thereafter covered using a wet cloth, and then this arrangement is dipped in the water reservoir. The cloth takes up the water from the bowl that evaporates and lowers 
the storage pot's temperature. The earthen bowl is isolated from the pot by wet sand from the ground (Kale et al., 2016).

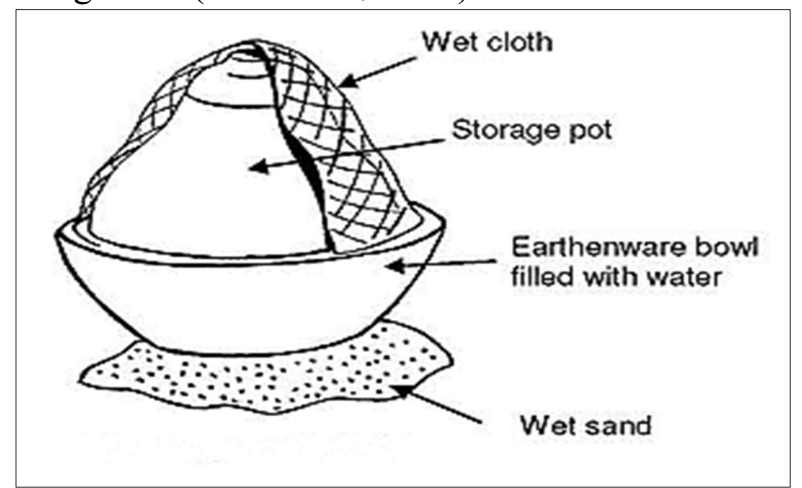

Figure 6. Pot type evaporative cooler (adapted from Roy and Khurdiya, 1985)

- Charcoal cooler: It is made of an open timber frame of nearly $50 \mathrm{~mm} \times 25 \mathrm{~mm}$ (Figure 7 ). One side of the frame is used as a hanging door. The whole wooden frame is wrapped up, inside and out, using a mesh. A $25 \mathrm{~mm}$ cavity is left in the mesh which is filled up with charcoal pieces. To achieve evaporative cooling, the charcoal is sprayed with water. This framework is installed on a pole with a metal cone to prevent spoilage due to rodents and rats. This whole setup is installed outside the building. A decent coating of grease is also used to prevent spoilage due to ants. The top of this system is generally solid and thatched; along with an overhang to constrain flying insects from the stored produce (Kale et al., 2016; Odesola and Onyebuchi, 2009).

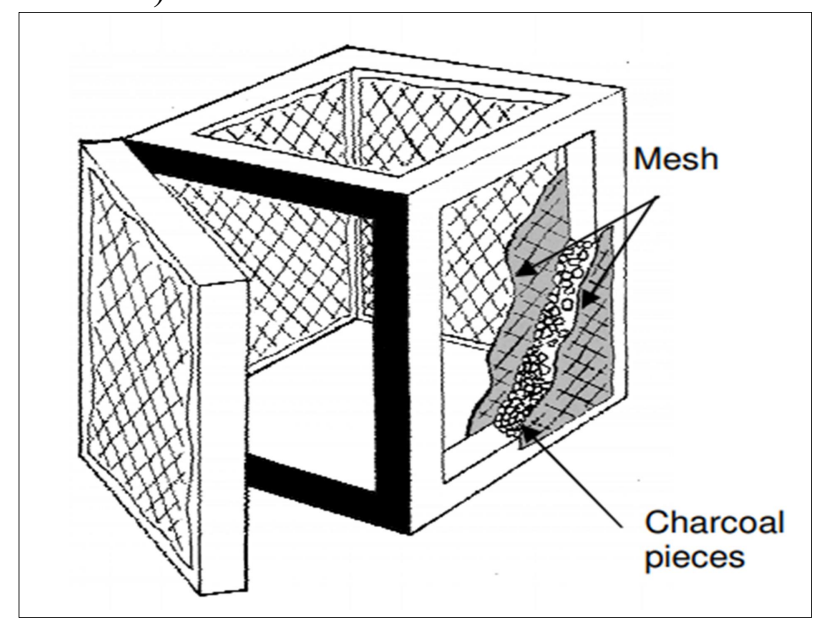

Figure 7. Charcoal cooler (adapted from Odesola and Onyebuchi, 2009).
- Zero Energy Cool Chambers: These chambers are designed on the principles of direct evaporative cooling. No electricity or power is required for their operation. The materials required for the construction (bricks, sand and bamboo) are also available easily (Figure 8). Zero energy cool chambers (ZECC) are double brick walled structures. The chamber walls are soaked in water, and the cavity is filled with sand. The chamber can be easily constructed by unskilled labour. This system can reduce the temperature of the crop by $10-15^{\circ} \mathrm{C}$ and maintain a high humidity of nearly $90 \%$. ZECC hence helps in retaining the quality and enhancing the shelf life of the fresh products. Such practices can avoid middlemen or intermediaries in retail chains for small and marginal farmers by storing produce for a few days. National Horticulture Board is also giving farmers a grant aid of $100 \%$ for ZECC (Khan et al., 2017). The details of construction, operation and precautions are given below (Kale et al., 2016; Khan et al., 2017).

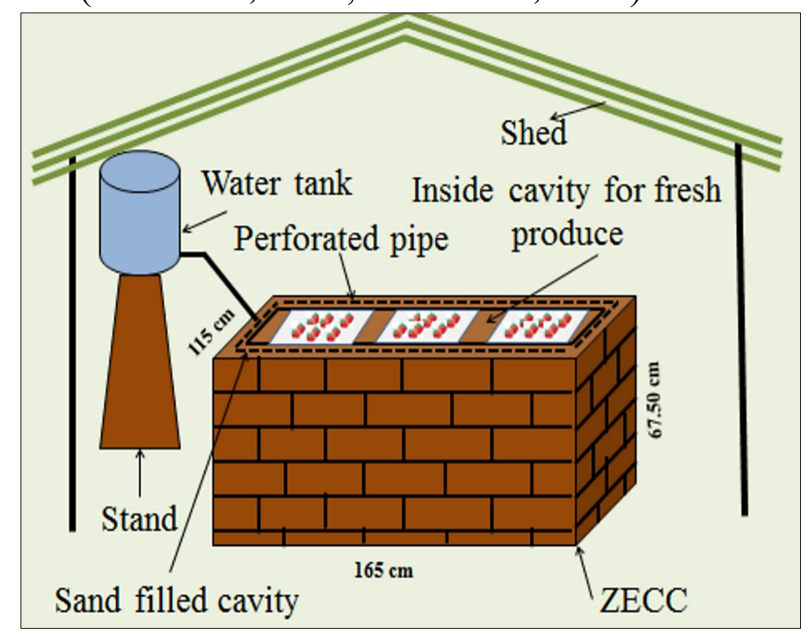

Figure 8. Zero energy cool chambers (adapted from Khalid et al., 2020).

\section{Construction of ZECC}

- An area is selected having a water source nearby

- Brick floor is made with dimensions of $165 \mathrm{~cm}$ $\mathrm{x} 115 \mathrm{~cm}$.

- Double-wall is set up with a height of $67.5 \mathrm{~cm}$, leaving a $7.5 \mathrm{~cm}$ cavity

- The chamber is imbibed with water 
- Fine riverbed sand is saturated with water and filled in the $7.5 \mathrm{~cm}$ cavity left in the double wall

- The top cover frame is made $(165 \mathrm{~cm} \times 115$ $\mathrm{cm})$ with bamboo and straw or dry grass

- Ensure sun or rain protection with a shed over the chamber

\section{Operation}

- The sand, top cover and bricks of the chamber should be kept wet with water

- Connect a drip line to an overhead water source to ensure a continuous water flow and maintain the required environment

- Fruits and vegetables must be stored in perforated plastic crates in this chamber

- Thin sheets of polythene should be used to cover these crates

Necessary precautions during ZECC construction

- Locate the system at a place which has abundant access to the airflow

- Avoid waterlogging by building the structure at an elevated place

- Good quality bricks with significant porosity should be used.

- No organic matter or clay should be present in the sand used.

- The sand and bricks used should be watersaturated

- Using a roof over can prevent direct solar exposure.

- Prefer crates made of plastic over wooden, fiberboard, bamboo baskets, gunny bags, etc.

- Avoid the contact of water with the fresh produce.

- Ensure cleanliness in the chamber and disinfect regularly using permitted fungicide, insecticide, or chemicals to protect against fungus, insects, rodents, pests or reptiles, etc.

Improved/ Modern storage methods/ High cost storage technologies

Several improved and novel packaging and storage technologies have been experimented and commercialized for fruits and vegetables. These include refrigerated storage, CAS, MAP and hypobaric storage. Important considerations for commercially adopting these technologies for bulklevel include cost-effectiveness, eco-friendliness, product quality and applicability range, storage area to product volume ratio, skill requirement, process control, energy requirement and safety aspects. Some improved storage technologies for horticultural crops are discussed below:

i. Cold storage: The product's respirational intensity is directly linked to the optimum temperature of the storage space. Lowering of temperature leads to a decline in the rate of respiration of the produce, which further reduces the rate of biochemical reaction and improves the shelf life of the product. A cold storage facility (Figure 9) is the heart of the cold chain employed in the market of fresh produce. A cold chain ensures quality maintenance right from harvest to consumer use (Elansari et al., 2019). Cold storage is usually a storage space maintained with the help of a non-toxic refrigerant and the walls insulated with a good insulator, like polyurethane foam (PUF) to minimize heat loss. Adequate storage is ensured by cold storages that maintain the desired fresh produce storage conditions combined with ventilation systems and humidity controllers (Sahoo et al., 2019).

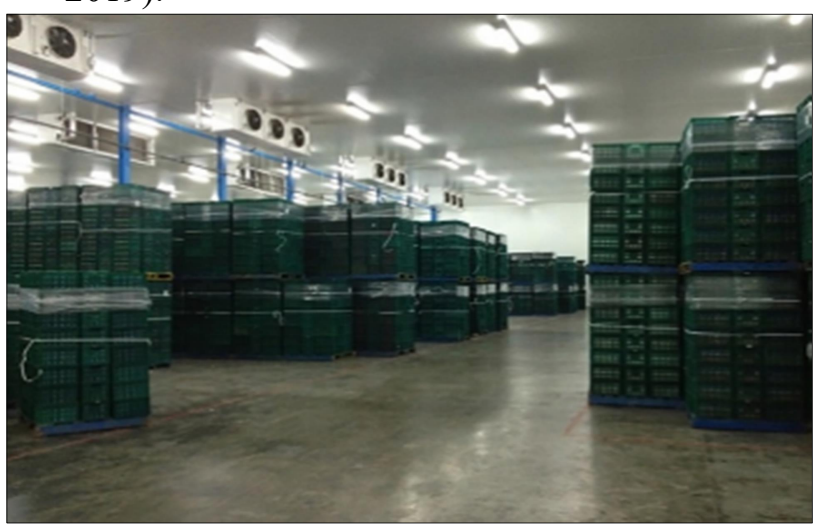

Figure 9. Cold storage (adapted from Elansari et al., 2019)

\section{Benefits}

- Reduces respiration rate and thus perishability

- Reduces transpiration: lessens shriveling, reduces water losses

- Decreases ethylene production: slows ripening

- Enhances resistance to ethylene action

- Reduces microbial activity

- Decreases browning and maintains texture, nutrients and flavour 
- Postpones ripening and reduces natural senescence (Kitinoja, 2013)

Post-harvest technologies for inhibiting or delaying chilling injury

When certain fruits are exposed to low (but not freezing) temperatures, they undergo chilling injuries. The chilling injuries lead to some physiological changes, including alterations to the metabolism, which can lead to the appearance of bruises on the fruit surface or an abnormal ripening (Sevillano et al., 2009). In modern storage facilities, care is being taken to delay or inhibit the development of chilling injuries during the storage period of sensitive horticultural produce. Storage parameters like changes in temperature, gaseous composition, or relative humidity control the incidence and extent of these injuries and are considered while storing sensitive fruit. These methods are generally used in industries. Examples include pretreatment at high temperature, moderate temperature conditioning, treating with $\mathrm{CO}_{2}$ before or during the storage, intermittent warming, CAS and MAP.

ii. CAS: In a CAS system, the produce is kept at reduced $\mathrm{O}_{2}$ and high $\mathrm{CO}_{2}$ concentrations with an appropriate temperature range and $\mathrm{RH}$
(Dhatt and Mahajan, 2007). Several commodities' shelf life can be extended up to 24 times the usual shelf life. The composition of $\mathrm{CO}_{2}$ and $\mathrm{O}_{2}$ levels in controlled atmosphere storage is kept within maintained and controlled levels in gas-tight containers or stores. The leakages in the walls and door of the storage area and the ripening produce's metabolic activities prompt a continuous change in the gas composition of the storage space. The gas composition is thus monitored periodically, and fresh air or nitrogen is input to maintain a predetermined level of headspace gas composition. It can also be done by passing the atmosphere of the store through a chemical for removing carbon dioxide. A system can be designed which initially flushes gases to lower the oxygen content and after that either injects carbon dioxide or allows it to cumulate through produce respiration. This atmosphere can then be maintained by scrubbing and ventilation (Khan et al., 2017). Table 2 describes the recommended conditions for some fruits and vegetables for which CAS is commercially used (Kader, 1992).

Table 2. Recommended conditions for controlled atmosphere storage of some horticultural crops (adapted from Kader, 1992)

\begin{tabular}{|c|c|c|c|}
\hline Fruits and vegetables & Temperature (C) & \% Oxygen & \% Carbon dioxide \\
\hline Apple & $0-5$ & $2-3$ & $1-2$ \\
\hline Bananas & $12-15$ & $2-5$ & $2-5$ \\
\hline Cantaloupe & $3-7$ & $3-5$ & $10-15$ \\
\hline Kiwifruit & $0-5$ & 2 & 5 \\
\hline Lettuce & $0-5$ & $2-5$ & 0 \\
\hline Nuts and dried fruits & $0-25$ & $0-1$ & $0-100$ \\
\hline Strawberry & $0-5$ & 10 & $15-20$ \\
\hline
\end{tabular}

\section{Benefits of CAS}

- It reduces the rate of respiration and ethylene production and hence, retards senescence of fresh products

- It decreases the responsiveness of fruits towards the ethylene action

- It prevents several physiological disorders, such as russet spotting in lettuce, chilling injury in a variety of products and some storage problems, including apple scalds

- The losses of some other vitamins, especially those susceptible to oxidation, can be prevented
- It has fungistatic effects and can prevent the incidence of various fungi and bacteria

- Insect attacks can be controlled

- It maintains the quantitative and qualitative aspects of the product for an extended period and hence helps improve their shelf life

\section{Potential negative effects}

- Very low volume of oxygen and/or a very high volume of carbon dioxide (depending upon the duration of treatment, type of food and temperature) can change aerobic into anaerobic respiration which can lead to fermentation 
- Some physiological disorders may be initiated or aggravated, for example, brown coloured stains on lettuce, blackheart in potatoes and brown heart in pears and apples

- Fruits such as mango, banana, tomato and pear can experience irregular ripening due to stress from an oxygen content below $2 \%$ or carbon dioxide content above 5\%, for more than 2 to 4 weeks

- Anaerobic respiration and fermentation due to low oxygen and high carbon dioxide volume can lead to the development of off-odours and off-flavours

- Fungi and other micro-organisms can penetrate in inadequate gas levels through plant tissues. Furthermore, at low levels of oxygen and/or very high levels of carbon dioxide, bacterial development, which is a potential risk in fresh produce (especially minimally processed horticultural products) can be facilitated (Dhatt and Mahajan 2007; Yahia et al., 2019)

iii. MAP: MAP includes storage of fresh produce in environments whose gas composition has been modified as compared to that of air to enhance the keeping quality, shelf life and to bring down the metabolic activity rate of the product stored (Coles et al., 2003). Figure 10 shows different processes taking place in a MAP. The MAP of fresh horticultural produce includes replacement of the gases in the package headspace with a composition of gases that are non-reactive and different from that of air. A composition of $\mathrm{CO}_{2}, \mathrm{O}_{2}$ and $\mathrm{N}_{2}$ is injected into the headspace that replaces the package atmosphere. The nature of fresh produce determines the composition and amount of gases being used. Some of the key factors affecting the effectiveness of MAP are the rate of respiration of the produce, oxygen and carbon dioxide permeability of package material, storage temperature and headspace volume of gases present inside the package (Soltani et al., 2015). MAP can be passively or actively modified.

Passive MAP: Rate of respiration of the produce and permeability of the packaging material play a crucial role in passive MAP. The oxygen use is proportional to the package atmosphere's carbon dioxide production due to the product respiration.
Eventually, the headspace gas composition reaches an equilibrium between the product respiration rate and package material permeability. During the equilibrium state, the total volume of $\mathrm{CO}_{2}$ production and $\mathrm{O}_{2}$ utilization become equivalent to gases permeated through the membrane surface.

Active MAP: In actively modified MAP, the package atmosphere is evacuated and then replaced with the desired composition of gases. This is done to ameliorate the modification of the in-package gas composition and further prevent stress-induced exposure to high gas concentrations (Zhang et al., 2015).

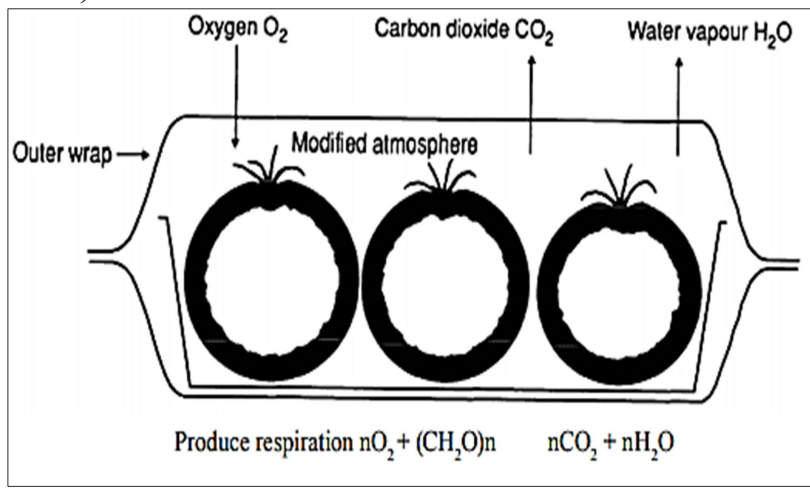

Figure 10. Processes in a modified atmosphere pack (adapted from Paine and Paine, 1992)

\section{Polymeric film applications for MAP of horticultural crops}

Flexible package structures have seen the most significant application of polymeric films for MAP (Mangaraj et al., 2009). Certain variables viz. oxygen and carbon dioxide permeability through film, film thickness, water vapour transmission rate (WVTR), the free volume within the package and the package surface area decide the degree of modification of the gases within the package (Ares et al., 2007; Beaudry, 1999; Cameron et al., 1994; Mahajan et al., 2008). These factors are key to determining the composition of in-package environment and humidity and hence can influence the product's deterioration rate. Several films have been used for MAP, the most commonly used being Low-Density Polyethylene, High-Density Polyethylene, Polypropylene, Polyvinyl Chloride, Polystyrene and Polyesters. Table 3 gives permeability of $\mathrm{O}_{2}$ and $\mathrm{CO}_{2}$ (determined at $25^{\circ} \mathrm{C}$ ) and water vapour transmission rate (determined at $38^{\circ} \mathrm{C}$ ) of some commonly used films in MAP (Farber et al., 2003). 
Storage structures for horticultural crops

Table 3. Permeabilities and water transmission rates of films commonly used for modified atmosphere packaging (25 $\mu \mathrm{m}$ film) (adapted from Ares et al., 2007).

\begin{tabular}{|c|c|c|c|}
\hline \multirow[t]{2}{*}{ Film } & \multicolumn{2}{|c|}{ Permeability, $\mathrm{cm}^{3} / \mathrm{m}^{2} \mathrm{~d}$ atm $\left(\right.$ at $\left.25^{\circ} \mathrm{C}\right)$} & \multirow{2}{*}{$\begin{array}{c}\text { Water transmission, } g / \mathrm{m}^{2} \mathrm{~d}(\text { at } \\
\left.38^{\circ} \mathrm{C} \text { and } 90 \% \mathrm{RH}\right)\end{array}$} \\
\hline & $\mathbf{O}_{2}$ & $\mathrm{CO}_{2}$ & \\
\hline Low-density Polyethylene & $3900-13000$ & $7700-77000$ & $6-23$ \\
\hline Medium-density Polyethylene & $2600-8300$ & $7700-38750$ & $8-15$ \\
\hline High-density Polyethylene & $520-4000$ & $3900-10000$ & $4-10$ \\
\hline Polypropylene & $1300-6400$ & $7700-21000$ & $4-11$ \\
\hline Polyvinyl Chloride & $150-2200$ & $450-8000$ & $30-40$ \\
\hline Polystyrene & $2000-7700$ & $10000-26000$ & $100-150$ \\
\hline Polyurethane & $800-1500$ & $7000-25000$ & $400-600$ \\
\hline Polyamide & 40 & $150-190$ & $84-3100$ \\
\hline
\end{tabular}

i. Hypobaric Storage / Low-Pressure Storage: Hypobaric pressure or sub-atmospheric pressure refers to a pressure below $101 \mathrm{kPa}$. Hypobaric storage is a relatively less understood type of controlled atmospheric storage in which a low-oxygen environment is created at sub-atmospheric pressure ranges; which in turn reduces the respiration rates and metabolism kinetics of commodities, thereby increasing storage life (Stenvers and Bruinsma, proportional to the decrease in the oxygen partial pressure (John, 2008). The product is stored under a partial vacuum in a chamber. The chamber is vented continuously with saturated air to maintain the low-oxygen partial pressure ranges. Generally, a $10 \mathrm{kPa}$ decrease in the air pressure (equal to an oxygen partial pressure of $2.1 \mathrm{kPa}$ ) permits a $2 \%$ reduction in oxygen concentration at normal atmospheric pressure (Vithu and Moses, 2017).

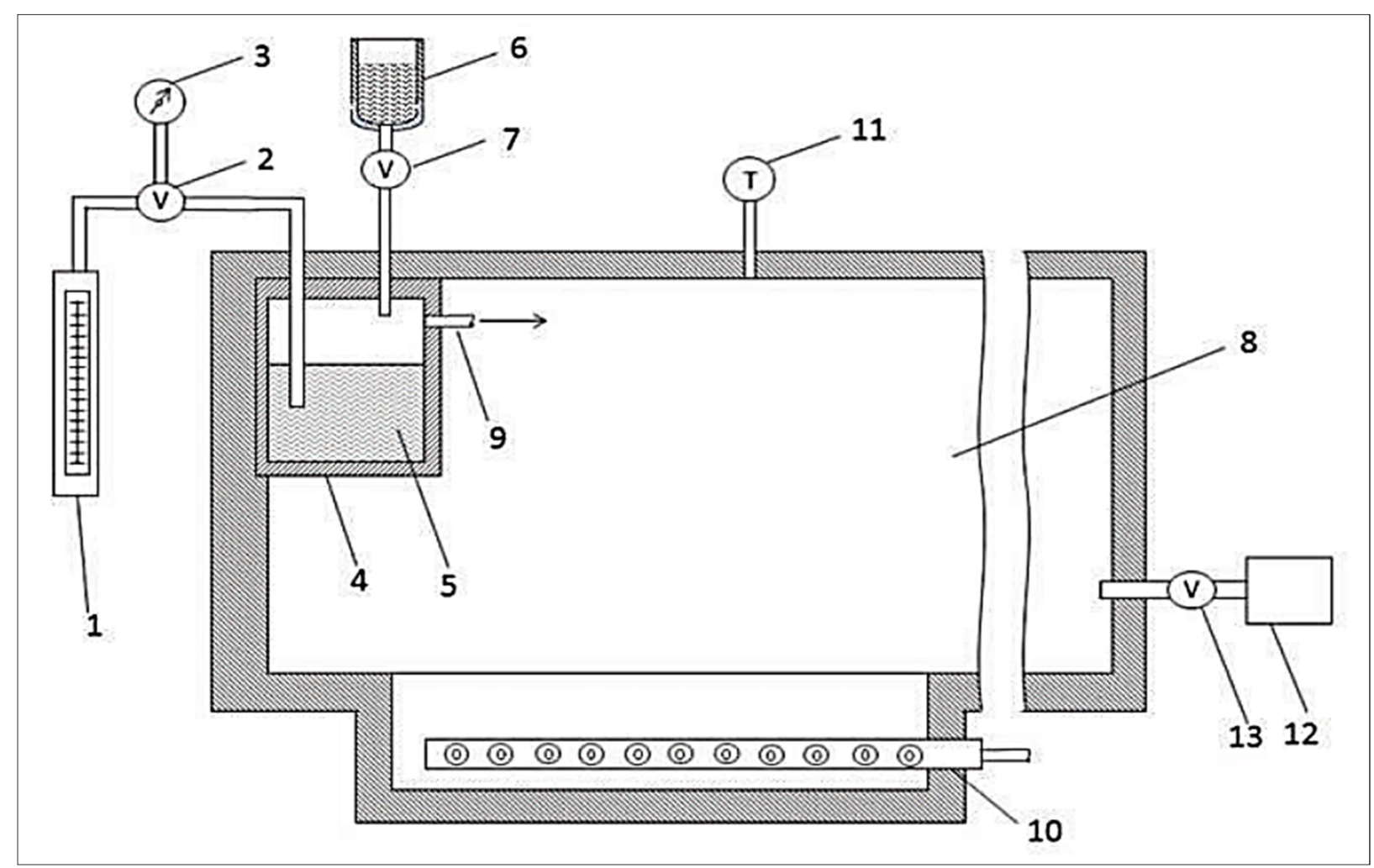

Figure 11. Hypobaric storage unit: (1) Airflow chamber, (2) needle valve, (3) vacuum gauge, (4) humidifier, (5) distilled water, (6) water reservoir, (7) valve, (8) storage chamber, (9) conduit, (10) refrigeration unit, (11) temperature gauge, (12) vacuum pump, (13) throttle valve (Vithu and Moses, 2017) 


\section{Working principle of a hypobaric storage system} A typical hypobaric system consists of a product storage chamber, a vacuum pump, a refrigeration unit and a humidifier (Figure 11). Air enters the system through the airflow chamber (1). A needle valve (2) is used to regulate the incoming lowpressure air (whose downstream pressure is measured using a vacuum gauge (3). Air is allowed to enter a humidifier (4) to increase the R.H. to about $80-100 \%$ (as in most cases). For this purpose, distilled water (5) from a water reservoir (6) is added periodically to the humidifier, with the help of a valve (7). The humidification system removes respiratory heat and any other additional heat received from the environment; thereby preventing water loss. Saturated air is supplied to the vacuum storage chamber (8) through a conduit (9). Food commodities are stored in this chamber under vacuum (usually 4-400 $\mathrm{mm} \mathrm{Hg}$ absolute). Storage temperature is an important parameter and is kept under control $\left(-2\right.$ to $\left.15^{\circ} \mathrm{C}\right)$ using a refrigeration unit (10) designed in the form of coolant tubes. A temperature gauge (11) shows the variation in temperature during storage. To ensure the low pressure in the storage chamber, a vacuum pump (12) is provided. A pressure regulator/throttle valve (13) controls the entry/exit of air from/ to the system (Burg, 1976).

\section{References}

Ares, G., Lareo, C. and Lema, P. 2007. Modified atmosphere packaging for postharvest storage of mushrooms. A review. Fresh Produce, 1(1): 32-40.

Basediya A. L., Samuel D. V. K. and Beera V. 2013. Evaporative cooling system for storage of fruits and vegetables - a review. Journal of Food Science and Technology, 50(3): 429-442.

Beaudry, R. M. 1999. Effects of $\mathrm{O}_{2}$ and $\mathrm{CO}_{2}$ partial pressure on selected phenomena affecting fruit and vegetable quality. Postharvest Biology and Technology, 15: $293-$ 303.

Burg, S.P. 1976. Low temperature hypobaric storage of metabolically active matter. US patents $3,958,028$ and $4,061,483$.

Burg, S.P. 2014. U.S. Patent No. 8,763,412. Washington, DC: U.S. Patent and Trademark Office.

Cameron, A. C., Beaudry, R. M., Banks, N. H. and Yelanich, M. V. 1994. Modified atmosphere packaging of blueberry fruit: modeling respiration and package oxygen partial

\section{Conclusion}

Post-harvest losses of horticultural crops due to short shelf life and improper storage are major problem for the farmers and food industries. Different storage structures are developed based on temperature and environment control to reduce these losses and retain the crop quality until their demand in the market. Storage structures like clamps, pits, cellar and evaporative cooling chambers are being traditionally used and help the farmers generate greater revenue. However, these are incompetent to store a bulk of products for an extended time. Innovations in evaporative cooling structures are coming up. Structures like Zero energy evaporative cooling structures and pot in pot design are beneficial when it comes to having better income with lesser inputs. Now, improved and modern techniques are also being utilized, which include storage in cold stores, CAS, MAP and hypobaric storage. Though these are costly, yet these techniques have proved effective in enhancing the shelf life of numerous horticultural crops by creating an appropriate storage environment for them. Different storage structures are being studied for different crop species, and there is an enormous scope as far as storage of horticultural crops is concerned.

pressures as function of temperature. Journal of the American Society for Horticultural Science, 119(3): 4539.

Coles, R., McDowell, D. and Kirwan, M. J. (Ed.) 2003. Food packaging technology (Vol. 5). CRC Press.

Dhatt, A. S. and Mahajan, B. V. C. 2007. Harvesting, handling and storage of horticultural crops.

Elansari, A. M., Yahia, E. M. and Siddiqui, W. 2019. Storage Systems. In Postharvest Technology of Perishable Horticultural Commodities, Woodhead Publishing. pp: 401-437.

El-Ramady, H. R., Domokos-Szabolcsy, É, Abdalla, N. A., Taha, H. S. and Fári, M. 2015. Postharvest management of fruits and vegetables storage. In Sustainable agriculture reviews, (pp. 65-152). Springer, Cham.

Farber, J. N., Harris, L. J., Parish, M. E., Beuchat, L. R., Suslow, T. V., Gorney, J. R., Garrett, E. H. and Busta, F. F. 2003. Microbiological safety of controlled and modified atmosphere packaging of fresh and fresh-cut produce. Comprehensive reviews in food science and food safety, 2: 142-160. 
John, J. 2008. A handbook on post-harvest management of fruits and vegetables. Daya publishing house, Delhi. p.119.

Kader, A. A. 1992. Postharvest biology and technology: An overview. In: A.A. Kader (ed.). Postharvest technology of horticultural crops.2nd ed. Univ. of California, Division of Agriculture and Natural Resources, Oakland. Publ. 3311: 15- 20.

Kale, S. J., Nath, P., Jalgaonkar, K. R. and Mahawar, M. K. 2016. Low cost storage structures for fruits and vegetables Handling in Indian Conditions. Indian Horticulture Journal, 6(3): 376-379.

Khalid, S., Majeed, M., Ullah, M. I., Shahid, M., Riasat, A. R., Abbas, T., Aatif, H. M. and Farooq, A. 2020. Effect of storage conditions and packaging material on postharvest quality attributes of strawberry. Journal of Horticulture and Postharvest Research, 3(2): 195-208.

Khan, F. A., Bhat, S. A. and Narayan, S. 2017. Storage Methods for Fruits and Vegetables. Sher-e-Kashmir University of Agricultural Sciences and Technology of Kashmir. Shalimar.

Kitinoja, L. 2013. Use of cold chains for reducing food losses in developing countries. Population, 6(1.23): 5-60.

Liberty J. T., Okonkwo, W. I. and Echiegu, E. A. 2013. Evaporative Cooling: A Postharvest Technology for Fruits and Vegetables Preservation. International Journal of Scientific \& Engineering Research, 4(8): 2257-2266.

Mahajan, P. V., Oliveira, F. A. R., Montanez, J. C. and Iqbal, T. 2008. Packaging design for fresh produce: an engineering approach. New Food, 11(1): 35-36.

Mangaraj, S., Goswami, T. K. and Mahajan, P. V. 2009. Applications of plastic films for modified atmosphere packaging of fruits and vegetables: a review. Food Engineering Reviews, 1(2): 133-158.

Nanda, S. K., Vishwakarma, R. K., Bathla, H. V. L., Rai, A. and Chandra, P. 2012. Harvest and post harvest losses of major crops and livestock produce in India. AICRP, (ICAR).

Ndukwu M. C. and Manuwa S. I. 2014. Review of evaporative cooling in preservation of fresh agricultural produce. International Journal of Agricultural and Biological Engineering, 7(5): 85-102.

Odesola I. F. and Onyebuchi, O. 2009. A review of porous evaporative cooling for the preservation of fruits and vegetables. Pacific Journal of Science and Technology, 10(2): 935-941.

Paine, F. A. and Paine, H. Y. (Ed.) 1992. A handbook of food packaging. Springer Science \& Business Media.

Rais, M. and Sheoran, A. 2015. Scope of supply chain management in fruits and vegetables in India. Journal of Food Process Technology, 6(3): 1-7.

Rees, D., Westby, A., Tomlins, K., Van Oirschot, Q., Cheema, M. U., Cornelius, E. and Amjad, M. 2012. Tropical root crops. Crop Post-Harvest: Science and Technology, Perishables, 3: 392-413.

Roy, S. K. and Khurdiya, D. S. 1985. Zero energy cool chamber. India Agricultural Research Institute: New Delhi, India. Research Bulletin, 43: 23-30.

Sahoo, K., Bandhyopadhyay, B., Mukhopadhyay, S., Sahoo, U., Kumar, T. S., Yadav, V. and Singh, Y. 2019. Cold Storage with Backup Thermal Energy Storage System. Progress in Solar Energy Technologies and Applications. pp: 181-232.

Sevillano, L., Sanchez-Ballesta, M. T., Romojaro, F. and Flores, F. B. 2009. Physiological, hormonal and molecular mechanisms regulating chilling injury in horticultural species. Postharvest technologies applied to reduce its impact. Journal of the Science of Food and Agriculture, 89(4): 555-573.

Soltani, M., Alimardani, R., Mobli, H. and Mohtasebi, S. S. 2015. Modified atmosphere packaging: A progressive technology for shelf-life extension of fruits and vegetables. Journal of Applied Packaging Research, 7(3): 33-59.

Stenvers, N. and Bruinsma, J. 1975. Ripening of tomato fruits at reduced atmospheric and partial oxygen pressures. Nature, 253: 532-533.

Vithu, P. and Moses, J. A. 2017. Hypobaric Storage of Horticultural Products: A Review. In Engineering Practices for Agricultural Production and Water Conservation, Apple Academic Press. pp: 155-170.

Yahia, E. M., Fadanelli, L., Mattè, P. and Brecht, J. K. 2019. Controlled Atmosphere Storage. In Postharvest Technology of Perishable Horticultural Commodities, Woodhead Publishing. pp: 439-479.

Zhang, M., Meng, X., Bhandari, B., Fang, Z. and Chen, H. 2015. Recent application of modified atmosphere packaging (MAP) in fresh and fresh-cut foods. Food Reviews International, 31(2): 172-193. 